\title{
Note from the Editor: Lasswell Prize announcement for Policy Sciences Volume 54 (2021)
}

The Harold D. Lasswell Prize is awarded to the best article in each volume of Policy Sciences that contributes most to the theory and practice of the policy sciences, as determined by a vote of the journal's international editorial board. The prize is named in honor of Harold D. Lasswell (1902-1978), a founder of this journal and noted contributor to the policy sciences.

The prize is accompanied by a monetary award of $\$ 500$ provided by the journal's publisher, Springer.

It gives me great pleasure to announce that the winners of the 2022 prize are Antti Gronow, Maria Brockhaus, Monica Di Gregorio, Aasa Karimo and Tuomas Ylä-Anttila for their article "Policy learning as complex contagion: how social networks shape organizational beliefs in forest-based climate change mitigation."

The article appeared in Policy Sciences 54(3): 529-556 (September 2021).

https://doi.org/10.1007/s11077-021-09418-2.

Publisher's Note Springer Nature remains neutral with regard to jurisdictional claims in published maps and institutional affiliations. 